Research Article

\title{
Experimental Investigation and Prediction of Compressive Strength of Ultra-High Performance Concrete Containing Supplementary Cementitious Materials
}

\author{
Jisong Zhang, ${ }^{1}$ Yinghua Zhao, ${ }^{1}$ and Haijiang $\mathrm{Li}^{2}$ \\ ${ }^{1}$ Institute of Road and Bridge Engineering, Dalian Maritime University, Dalian, Liaoning 116026, China \\ ${ }^{2}$ Cardiff School of Engineering, Cardiff University, Queen's Buildings, The Parade, Cardiff CF24 3AA, UK \\ Correspondence should be addressed to Jisong Zhang; jisong_z@hotmail.com
}

Received 3 October 2017; Accepted 13 November 2017; Published 31 December 2017

Academic Editor: Renal Backov

Copyright (c) 2017 Jisong Zhang et al. This is an open access article distributed under the Creative Commons Attribution License, which permits unrestricted use, distribution, and reproduction in any medium, provided the original work is properly cited.

Ultra-high performance concrete (UHPC) has superior mechanical properties and durability to normal strength concrete. However, the high amount of cement, high environmental impact, and initial cost are regarded as disadvantages, restricting its wider application. Incorporation of supplementary cementitious materials (SCMs) in UHPC is an effective way to reduce the amount of cement needed while contributing to the sustainability and cost. This paper investigates the mechanical properties and microstructure of UHPC containing fly ash (FA) and silica fume (SF) with the aim of contributing to this issue. The results indicate that, on the basis of $30 \%$ FA replacement, the incorporation of $10 \%$ and $20 \%$ SF showed equivalent or higher mechanical properties compared to the reference samples. The microstructure and pore volume of the UHPCs were also examined. Furthermore, to minimise the experimental workload of future studies, a prediction model is developed to predict the compressive strength of the UHPC using artificial neural networks (ANNs). The results indicate that the developed ANN model has high accuracy and can be used for the prediction of the compressive strength of UHPC with these SCMs.

\section{Introduction}

Ultra-high performance concrete (UHPC) is a new type of concrete that is characterised by its high compressive strength and excellent durability [1]. The benefits of using UHPC in a structure include reducing the amount of concrete needed, namely, sliming the beams, columns, and slabs, which in turn increases the overall net space, reduces labour and equipment needed for erection, and reduces the construction time. However, given the recognised benefits, it is surprising that UHPC is not used widely. Its low use can be attributed to high cost and great environmental impact per cubic meter of concrete. Particularly, owing to the absence of a coarse aggregate, the amount of cement used in UHPC is relatively high, namely, $900-1200 \mathrm{~kg} / \mathrm{m}^{3}$. Globally, the production of cement accounts for more than 5\% of anthropogenic carbon dioxide emissions each year. As such, much attention has been paid to producing UHPC with less cement and a lower environmental impact while providing equivalent properties [2].

Supplementary cementitious materials (SCMs), such as fly ash (FA), blast-furnace slag, and silica fume (SF), are industrial by-products that are widely used in concrete for various purposes [3]. In the field of UHPC, much attention has been devoted to reducing the cement content. For example, Ghafari et al. used $950 \mathrm{~kg} / \mathrm{m}^{3}$ cement and $250 \mathrm{~kg} / \mathrm{m}^{3}$ SF to produce UHPC [4]. Yu et al. produced UHPC with $620 \mathrm{~kg} / \mathrm{m}^{3}$ cement to obtain a compressive strength of $100 \mathrm{MPa}$ [2]. Aldahdooh et al. utilised $638 \mathrm{~kg} / \mathrm{m}^{3}$ cement to design an UHPC with $120 \mathrm{MPa}$ of compressive strength [5]. The use of such materials provides great potential for $\mathrm{CO}_{2}$ emission reduction over the cement-clinkering process. Although much work has been conducted on this aspect, there is still plenty of scope for further investigation. FA, a by-product of the industrial waste, has been proved to be useful in addressing the challenges of minimising industrial wastes and sustainable construction. It is worth mentioning 
TABle 1: Physical properties and chemical composition of raw materials.

\begin{tabular}{lccccccccc}
\hline Material & Density $\left(\mathrm{kg} / \mathrm{m}^{3}\right)$ & $\mathrm{D} 10(\mu \mathrm{m})$ & $\mathrm{D} 50(\mu \mathrm{m})$ & $\mathrm{D} 90(\mu \mathrm{m})$ & $\mathrm{SSA}\left(\mathrm{m}^{2} / \mathrm{g}\right)$ & $\mathrm{CaO}(\%)$ & $\mathrm{SiO}_{2}(\%)$ & $\mathrm{Al}_{2} \mathrm{O}_{3}(\%)$ & $\mathrm{Fe}_{2} \mathrm{O}_{3}(\%)$ \\
\hline Cement & 3100 & 2.02 & 14.5 & 44.9 & 0.35 & 61.8 & 20.3 & 5.1 & 3.4 \\
$\mathrm{FA}$ & 2300 & 2.80 & 15.9 & 55.6 & 0.33 & 3.26 & 53.5 & 20.6 & 3.18 \\
$\mathrm{SF}$ & 2160 & 0.09 & 0.35 & 12.1 & 21.7 & - & 91.2 & 0.41 & 0.32 \\
\hline
\end{tabular}

that, in China, over 620 million tons of FA is generated every year. However, the utilisation ratio is still below 50\% [6]. Meanwhile, to overcome the problem of FA's slowdown of the pozzolanic reaction, the incorporation of SF is supposed to expedite the pozzolanic reaction at an early stage as the SF particles can fill the pores between larger particles of cement, sand, and other fillers. Furthermore, the high-temperature curing and fine quartz powder used in UHPC also lead to high cost and energy consumption. However, production of UHPC using common sand with normal temperature curing has rarely been investigated in the past, and thus, it is investigated in this work to broaden the knowledge base and promote lower UHPC costs.

On the other hand, the essential properties of UHPC with SCMs need to be validated experimentally because of the unclear combination effects of different materials and dosages being used in the mixture. Laboratory experiments are often costly, time-consuming, and labour-intensive. To minimise the experimental workload of property assessment and mix design, probabilistic models can be successfully employed to forecast the compressive strength of normal concrete. However, these prediction models are inadequate for analysing the properties of UHPC because of the large volume of SCMs used. As such, the issue of development of a model for predicting the properties of the UHPCs has been recently addressed. Little research work has been conducted on the prediction of the properties of UHPCs containing supplementary materials. Some researchers have conducted studies on modelling the properties of self-compacting concrete, normal concrete, and high-performance concrete (HPC). Mousavi et al. predicted the compressive strength for HPC by using gene expression programming [7]. Erdal applied decision trees for HPC strength prediction [8]. Among these prediction methods, artificial neural networks (ANNs) have obvious advantages due to their ability to solve very complex problems with sufficient accuracy. Moreover, they have been used in a wide range of civil engineering areas, such as concrete durability, workability, mechanical properties, and structure [9].

The objective of this study is twofold. Firstly, it attempts to replace up to $50 \%$ of the cement in UHPC with SCMs, namely, FA and SF in different proportions. Emphasis is placed on the synergistic effects and optimum proportion for the best mechanical properties (compressive strength). The microstructure is also examined. Secondly, it aims to evaluate the possibility of using the ANN to predict the compressive strength of UHPC containing SCMs. The prediction model used 11 input variables, which included the mass of sand, cement, water, coarse aggregate, FA, SF, and superplasticiser, the water-to-cement equivalent ratio, the aggregate-to-cement equivalent ratio, the fine aggregate
TABLe 2: Mixture proportions of designed concrete $\left(\mathrm{kg} / \mathrm{m}^{3}\right)$.

\begin{tabular}{lccccccc}
\hline Number & Cement & FA & SF & Sand & Water & SP & W/B \\
\hline Reference (C1) & 875 & 0 & 44 & 1273 & 202 & 6.9 & 0.22 \\
FA30SF5 (C2) & 612 & 263 & 44 & 1273 & 202 & 9.5 & 0.22 \\
FA30SF10 (C3) & 568 & 263 & 88 & 1273 & 202 & 10.6 & 0.22 \\
FA30SF15 (C4) & 524 & 263 & 132 & 1273 & 202 & 11.3 & 0.22 \\
FA30SF20 (C5) & 480 & 263 & 176 & 1273 & 202 & 11.9 & 0.22 \\
\hline
\end{tabular}

ratio, and the difference between the minimum and maximum values of the aggregate $\left(D_{\max }-D_{\min }\right)$. Emphasis is placed on the accuracy of predicting the compressive strength of UHPC with the SCMs. Finally, a comparison between the predicted results and experimental data is given by evaluating the root mean square error (RMSE), mean absolute percentage error (MAPE), and absolute fraction of variance $\left(R^{2}\right)$.

\section{Experimental Procedure}

2.1. Raw Materials. The cement used in this study was labelled as CEM I/52.5 R and was produced in accordance with the Chinese Standard GB175-2007. China ISO Standard Sand (in accordance with EN196-1 and ISO 679) was used as the aggregate with fractions of $0-2 \mathrm{~mm}(\mathrm{D} 10=320 \mu \mathrm{m}$, $\mathrm{D} 50=930 \mu \mathrm{m}$, and $\mathrm{D} 90=1600 \mu \mathrm{m})$. A commercially available superplasticiser (polycarboxylate ether, powder, and water-reducing ratio $>30 \%$ ) was employed to adjust the workability of the concrete. Fly ash (FA) and silica fume (SF) were used to replace the cement. The physical and chemical properties of these materials are listed in Table 1.

2.2. Mixture Proportions. In this work, modified A\&A theory is used to design the mix proportion of UHPC [10]. The reference UHPC has the highest cement content $\left(875 \mathrm{~kg} / \mathrm{m}^{3}\right)$. Afterwards, the volume of FA is held constant at $30 \%$ replacement level, and the SF volume is increased in increments of 5\%. For example, FA30SF 20 has $30 \%$ of the cement replaced by FA and $20 \%$ of the cement replaced by $\mathrm{SF}$. The water-to-binder ratio $(\mathrm{W} / \mathrm{B})$ is fixed at 0.22 , and the total binder content is $919 \mathrm{~kg} / \mathrm{m}^{3}$. The mix design for each group is presented in Table 2 .

A JJ-5 cement mortar mixer with two revolving speeds (140 or $285 \mathrm{rpm}$ ) in accordance with BS EN 196-1 is used to produce the mixture [11]. In total, $4 \mathrm{~min} 30 \mathrm{~s}$ is required to produce UHPC in the mixing procedure. After that, the slump flow of the fresh concrete is examined according to BS EN 1015-3. The amount of superplasticiser is adjusted until a constant flow value between 250 and $280 \mathrm{~mm}$ is achieved at a W/B ratio of 


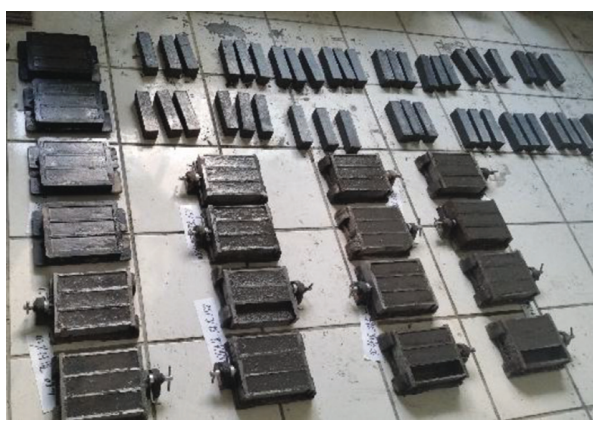

Figure 1: Preparation of concrete specimens.

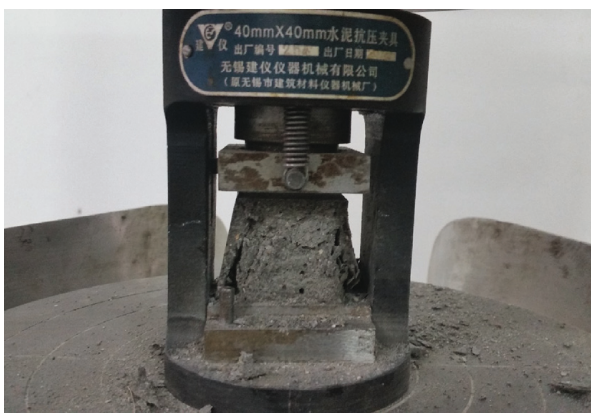

Figure 2: Compressive strength testing.

0.22 . Finally, the fresh mixture is cast into steel moulds of $40 \times 40 \times 160 \mathrm{~mm}$ (Figure 1) and compacted using a vibrating table for $1 \mathrm{~min}$. After 24 hours, the specimen is demoulded and cured at $20 \pm 2^{\circ} \mathrm{C}, \mathrm{RH}>90 \%$ for the required time.

2.3. Strength Testing and Microstructure Examination. Compressive strength is examined according to BS EN 196-1 (Figure 2). At least three samples were tested for each group at different ages ( $7,28,90$, and 365 days). The average values of three samples are reported in this study.

For the SEM test, the sample is cut into a small cube of $1 \times 1 \times 1 \mathrm{~cm}$ after 90 days. For the pore size distribution test, a sample of approximately $1.7-2.5 \mathrm{~g}$ is extracted from the mixture and tested using an ASAP 2020 at 365 days. The liquid nitrogen was at a temperature of $-197^{\circ} \mathrm{C}$. The BarrettJoyner-Halenda $(\mathrm{BJH})$ adsorption and desorption cumulative volume of the pores was between 1.7 and $300 \mathrm{~nm} \mathrm{[12].}$ The test lasted about 10 hours. The data for the cumulative pore volume and area were obtained from the ASAP 2020 straightway.

\section{Experimental Results}

3.1. Compressive Strength. The compressive strengths of the UHPC at 7, 28, 90, and 365 days are presented in Figure 3. It is apparent that the compressive strength of UHPCs decreases with increased FA only. However, in combination with SF, the flexural strength of the UHPC increases. With the increase of SF, the compressive strength of the UHPC increased gradually. The maximum compressive strength was obtained with C5 (FA30SF20), which is followed by C1

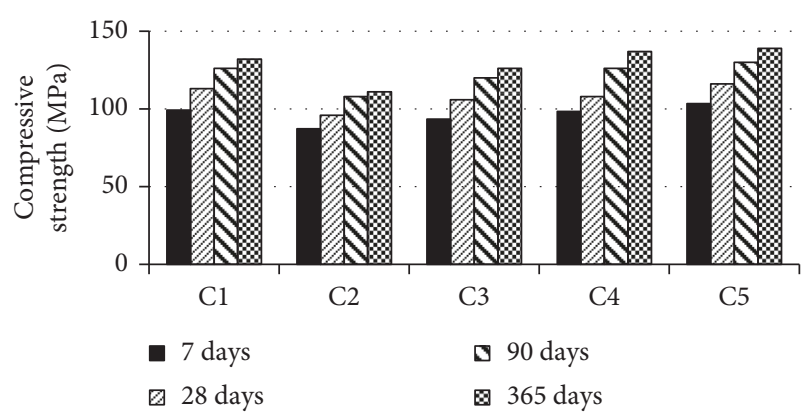

Figure 3: Compressive strength of UHPC.

and C4. This means that, with a total of $50 \%$ cement replacement, the compressive strength of $\mathrm{C} 5$ is equivalent to that of C1,that is, it is marginally higher than that of the reference sample. Furthermore, the compressive strength of each group increases with the time, regardless of concrete type. At the age of 7 days, the lowest compressive strength was obtained with $\mathrm{C} 2$, which can be attributed to the fact that FA slows down early strength development. At 28 days, the highest compressive strength was obtained with $\mathrm{C} 5$, followed by $\mathrm{C} 1$ and $\mathrm{C} 4$. This fact can be explained by the filler effect of SF, which is responsible for the strength enhancement at early ages. At 365 days, the compressive strengths of $\mathrm{C} 2$ and $\mathrm{C} 3$ approach that of $\mathrm{C} 1$, while the compressive strengths of both $\mathrm{C} 4$ and $\mathrm{C} 5$ exceeded that of C1. Sample C5 has a cement content of $480 \mathrm{~kg} / \mathrm{m}^{3}$, which indicates that it is possible to design UHPCs with low cement content.

It has been reported that the $\mathrm{CaO} / \mathrm{SiO}_{2}$ ratio has a strong effect on the strength development and that the optimal ratio of $\mathrm{CaO} / \mathrm{SiO}_{2}$ is approximately $1.30[13,14]$. In this study, the $\mathrm{CaO} / \mathrm{SiO}_{2}$ ratios of $\mathrm{C} 1$ to $\mathrm{C} 5$ are $2.46,1.22,1.02,0.86$, and 0.72 , respectively. However, the $\mathrm{C} 2$ group did not exhibit better compressive strength, even though the $\mathrm{CaO} / \mathrm{SiO}_{2}$ ratio was closest to 1.3. As such, it can be concluded that the $\mathrm{CaO} / \mathrm{SiO}_{2}$ ratio should be used with caution and preferably in conjunction with the fineness and $\mathrm{Al} / \mathrm{Si}$ or $\mathrm{Ca} /(\mathrm{Si}+\mathrm{Al})$ ratio as a compressive strength predictor.

To clarify the efficiency of SCMs on compressive strength, the effect of FA + SF can be expressed as an efficiency factor ( $k$-value) [15-17]. A $k$-value approaching one means that the addition is equivalent to cement. Based on the experimental results in this work, the $k$-values for FA30SF5, FA30SF10, FA30SF15, and FA30SF20 were 0.88 , $0.95,1.00$, and 1.03 , respectively.

3.2. Microstructure Examination. The microstructure of concrete can influence the mechanical properties and could be determined by SEM observation [18]. It can be seen from Figure 4 that FA30SF20 has the least number of capillary pores and the densest matrix compared to FA30SF5, which is consistent with the compressive strength results: it had higher compressive strength. This indicates a positive effect of SF on the microstructure as well as the strength enhancement. 


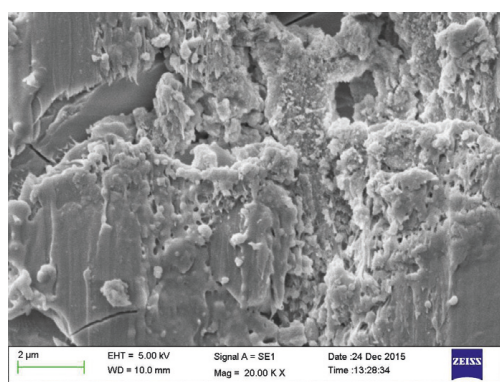

(a)

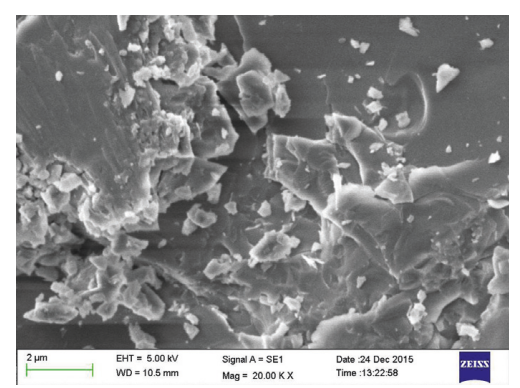

(b)

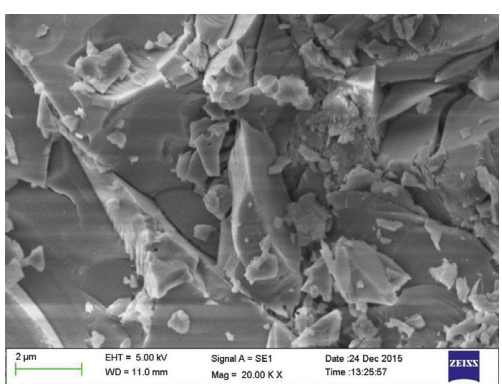

(c)

FIgURE 4: SEM micrographs of UHPC: (a) C2, (b) C3, and (c) C5.

TABLE 3: Pore size distribution for designed UHPC.

\begin{tabular}{lccccccc}
\hline Number & $\begin{array}{c}>200 \mathrm{~nm} \\
\left(10^{-3} \mathrm{~cm}^{3} / \mathrm{g}\right)\end{array}$ & $\begin{array}{c}110-200 \mathrm{~nm} \\
\left(10^{-3} \mathrm{~cm}^{3} / \mathrm{g}\right)\end{array}$ & $\begin{array}{c}40-110 \mathrm{~nm} \\
\left(10^{-3} \mathrm{~cm}^{3} / \mathrm{g}\right)\end{array}$ & $\begin{array}{c}10-40 \mathrm{~nm} \\
\left(10^{-3} \mathrm{~cm}^{3} / \mathrm{g}\right)\end{array}$ & $\begin{array}{c}<10 \mathrm{~nm} \\
\left(10^{-3} \mathrm{~cm}^{3} / \mathrm{g}\right)\end{array}$ & $\begin{array}{c}\text { Total pore volume } \\
\left(\mathrm{cm}^{3} / \mathrm{g}\right)\end{array}$ & $\begin{array}{c}\text { Total pore area } \\
\left(\mathrm{m}^{2} / \mathrm{g}\right)\end{array}$ \\
\hline $\mathrm{C} 1$ & 0.563 & 0.613 & 1.287 & 1.683 & 0.815 & 0.0050 & 0.969 \\
$\mathrm{C} 2$ & 0.758 & 0.985 & 2.136 & 2.274 & 2.659 & 0.0088 & 1.586 \\
$\mathrm{C} 3$ & 0.702 & 0.816 & 1.742 & 1.987 & 2.063 & 0.0073 & 1.343 \\
$\mathrm{C} 4$ & 0.626 & 0.693 & 1.558 & 1.669 & 1.552 & 0.0061 & 1.159 \\
$\mathrm{C} 5$ & 0.537 & 0.572 & 1.241 & 1.533 & 0.762 & 0.0047 & 0.932 \\
\hline
\end{tabular}

The BJH method can be used to quantify small pores in the range of $2-50 \mathrm{~nm}[19,20]$. As an exploratory attempt, the present work used this method to quantify the pore size and distribution of the developed UHPCs. The pore size range, total volume, and area of the UHPCs are shown in Table 3. The pore volume and area decrease with increasing compressive strength. When the pore volume and area are at their lowest, the compressive strength is at its highest for the developed UHPCs.

\section{ANN Model for Prediction of Compressive Strength}

4.1. Fundamental Data Collection. To evaluate the possibility of predicting the compressive strength of UHPCs incorporating SCMs, namely, FA and SF, an ANN model was constructed using 78 groups of experimental data from 11 literature sources [5, 15, 21-29], including the results from this work. Table 4 details the data sources and variables. In total, 11 input variables were selected to build the model employed in this study. They include the mass of cement $(C)$, sand $(S)$, water $(W)$, coarse aggregate (CA), FA, $\mathrm{SF}$, and superplasticiser (SP), the water-to-cement equivalent ratio $\left(W / C_{\text {eq }}\right)$, the aggregate-to-cement equivalent ratio $\left((S+\mathrm{CA}) / C_{\mathrm{eq}}\right)$, the fine aggregate ratio $(S /(S+\mathrm{CA}))$, the $D_{\max }-D_{\min }$, and the compressive strength $\left(f_{\mathrm{cu}}\right)$.

4.2. ANN Model Development. The ANN model in this work is composed of one input level, one hidden level, and an output level, as shown in Figure 5. The variables utilised in this study were as follows: (i) Amount of input variables $=11$

(ii) Amount of hidden levels $=1$

(iii) Amount of hidden levels units $=10$

(iv) Amount of output variables $=1$

(v) Learning rate $=0.1$

(vi) TrainParam.epochs $=100$

In this study, a tansig function has been used to calculate the predicted value through

$$
f_{\mathrm{cu}}(j)=\tan \operatorname{sig}(x)=\frac{e^{x}-e^{-x}}{e^{x}+e^{-x}}
$$

To examine the deviation between predicted values and experimental values, the root mean square error (RMSE), the mean absolute percentage error (MAPE), and the absolute fraction of variance $\left(R^{2}\right)$ were employed to assess the performance of the ANN, as expressed by (2)-(4), respectively.

$$
\begin{aligned}
\mathrm{RMSE} & =\sqrt{\left(\frac{1}{p}\right) \times \sum_{j}\left\|t_{j}-o_{j}\right\|^{2}}, \\
R^{2} & =1-\left(\frac{\sum_{j}\left(t_{j}-o_{j}\right)^{2}}{\sum_{j}\left(o_{j}\right)^{2}}\right), \\
\text { MAPE } & =\left(\frac{o-t}{o}\right) \times 100,
\end{aligned}
$$

where $o$ and $t$ are the experimental value and predicted value of the network and $p$ is the total number of groups. 
TABle 4: Details of data and their sources.

\begin{tabular}{lccccccccccc}
\hline Source & {$[21]$} & {$[22]$} & {$[23]$} & {$[24]$} & {$[25]$} & {$[26]$} & {$[27]$} & {$[28]$} & {$[15]$} & {$[5]$} & This work \\
No. & 4 & 2 & 3 & 27 & 3 & 6 & 16 & 3 & 1 & 9 & 4 \\
\hline$C\left(\mathrm{~kg} / \mathrm{m}^{3}\right)$ & $376-940$ & $401-729$ & $582-600$ & $467-993$ & $450-810$ & $745-778$ & $488-708$ & 960 & 413 & $638-1063$ & $480-875$ \\
$S\left(\mathrm{~kg} / \mathrm{m}^{3}\right)$ & $936-1180$ & 1230 & $1040-70$ & $952-1230$ & $616-797$ & $583-1166$ & $368-496$ & 960 & 790 & $552-1184$ & 1273 \\
$\mathrm{CA}\left(\mathrm{kg} / \mathrm{m}^{3}\right)$ & 0 & 0 & 0 & 0 & $923-1195$ & $0-583$ & $595-920$ & 0 & 968 & 0 & 0 \\
$W\left(\mathrm{~kg} / \mathrm{m}^{3}\right)$ & 125 & 200 & $148-173$ & $126-331$ & $90-162$ & $167-181$ & $140-165$ & $203-256$ & 155 & $153-229$ & 202 \\
$\mathrm{FA}\left(\mathrm{kg} / \mathrm{m}^{3}\right)$ & $188-564$ & $0-328$ & $260-268$ & $0-369$ & 0 & $181-189$ & 0 & 0 & 118 & 0 & 263 \\
$\mathrm{SF}\left(\mathrm{kg} / \mathrm{m}^{3}\right)$ & 28 & 124 & 25 & $0-80$ & $50-90$ & $186-194$ & $29-208$ & 240 & 59 & $159-265$ & $44-176$ \\
$\mathrm{SP}\left(\mathrm{kg} / \mathrm{m}^{3}\right)$ & 55 & 30 & $12.9-13.5$ & $15-34$ & 18 & $27-28$ & $11-34$ & 24 & 8 & $45-74$ & $6.9-17.3$ \\
$W / C_{\text {eq }}$ & $0.08-0.11$ & $0.20-0.26$ & $0.20-0.24$ & $0.13-0.39$ & 0.16 & $0.14-0.15$ & $0.14-0.26$ & $0.14-0.18$ & 0.27 & $0.14-0.16$ & $0.21-0.25$ \\
$(S+\mathrm{CA}) / C_{\text {eq }}$ & $0.78-0.80$ & $1.26-1.58$ & $1.41-1.42$ & $1.04-1.48$ & $1.55-3.62$ & $0.94-0.98$ & $1.20-1.81$ & 0.67 & 3.04 & $0.37-1.11$ & $1.32-1.58$ \\
$S /(S+\mathrm{CA})$ & 1.00 & 1.00 & 1.00 & 1.00 & 0.40 & $0.50-1.00$ & $0.35-0.39$ & 1.00 & 0.45 & 1.00 & 1.00 \\
$D_{\max }-D_{\text {min }}(\mathrm{mm})$ & 1.60 & 0.50 & 1.56 & 1.10 & 19 & $1.1-9.4$ & 18 & 0.1 & 16 & 1.18 & 1.56 \\
$f_{\text {cu }}(\mathrm{MPa})$ & $150-184$ & $124-166$ & $92-102$ & $85-130$ & $130-138$ & $155-185$ & $86-123$ & $135-150$ & 118 & $139-165$ & $109-114$ \\
\hline
\end{tabular}

No. $=$ number of collected specimens, $C=$ cement,$S=$ sand,$C A=$ coarse aggregate, $W=$ water, $F A=$ fly ash,$S F=$ silica fume, $S P=$ superplasticiser, $W / C_{\text {eq }}=$ water to $C_{\text {eq }}$ ratio, $D_{\max }=$ maximum aggregate size, $D_{\min }=$ minimum aggregate size, and $f_{\mathrm{cu}}=$ compressive strength at 28 days.

4.3. Result Comparison. A comparison between the predicted and experimental results is given in Table 5. It can be seen from Table 5 that the largest and smallest absolute errors between the two sets are $10.7 \mathrm{MPa}$ and $0.1 \mathrm{MPa}$, respectively, with most in the range of $0.1-6 \mathrm{MPa}$. Furthermore, the maximum and minimum relative errors are $9.2 \%$ and $0.1 \%$, respectively, and the mean relative error is $3.17 \%$, which can be considered as fit and acceptable. However, some of the data are not suitably accurate, which can be explained by the following reasons: firstly, the characteristics of cement and supplementary materials, such as physical properties (e.g., specific surface area and particle size distribution) and chemical properties (e.g., oxide composition, phase composition, and amorphous content), are not considered as an input factor as they are not reported in all the literature sources. Secondly, the different shapes and strengths of the aggregates also affect the compressive strength of the UHPCs. In addition, the different curing conditions and test environments in different laboratories also have an indirect influence on the compressive strength.

The MAPE and RMSE from the ANN model are 0.0026\% and $4.6564 \%$, respectively. They are both very low, indicating that the difference between the predicted and experimental values is minor. $R^{2}$ is 0.9986 , almost equal to one, indicating that the ANN model has high precision. The above three criteria demonstrate that it is feasible to predict the compressive strength of UHPCs containing SCMs with low error using the developed ANN model.

The deviation between the predicted and experimental values for each group is shown in Figure 6. The predicted values are very close to the corresponding experimental values. The predicted values versus the experimental values are plotted in Figure 7, from which it can be concluded that the developed ANN model gives a good fit to the experimental values. The performance of the ANN training process is shown in Figure 8, which presents the training epochs with the variation of the mean square error.

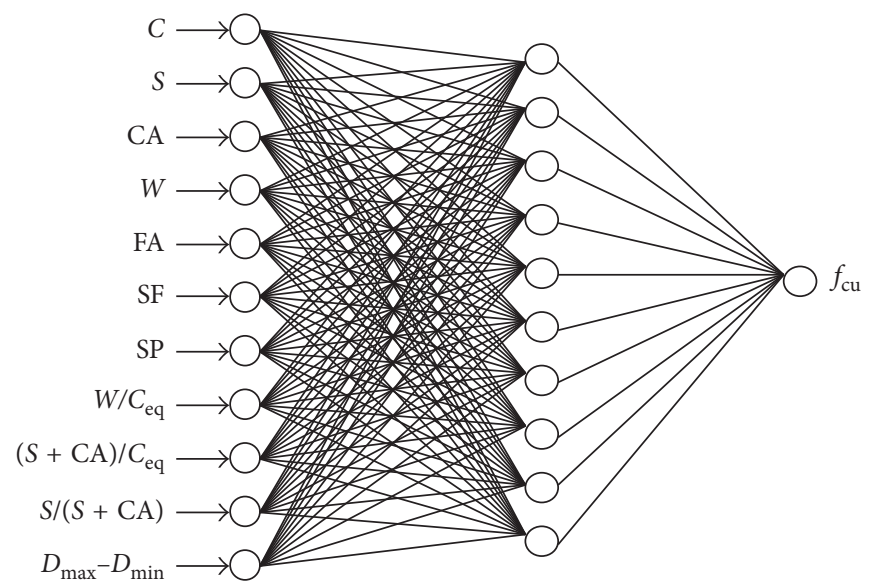

FIgURE 5: Constructed ANN model.

Therefore, it can be concluded that it is possible to predict the compressive strength of UHPC including SF and FA using the developed ANN model. Instead of using the conventional variables in the prediction model, the inclusion of factors such as the amount of SF and FA, the water-tocement equivalent ratio, and the difference between the minimum and maximum values of the aggregate enables the prediction of the compressive strength with reasonable accuracy. However, the performance of the developed ANN model could be further improved by adding more factors, such as the characteristics of the cement, supplementary materials, and aggregate.

\section{Conclusion}

In this study, the compressive strength and microstructure of UHPCs with SCMs were investigated. To minimise the experimental workload of future studies, an ANN model was developed to predict the compressive strength of the UHPCs. From the experimental work and the modelling, the following conclusions can be drawn. 
TABLE 5: Comparison between the predicted and experimental values.

\begin{tabular}{|c|c|c|c|c|}
\hline Number & $A(\mathrm{MPa})$ & $P(\mathrm{MPa})$ & Abs (MPa) & $k(\%)$ \\
\hline (1) & 113.0 & 114.9 & 1.9 & 1.7 \\
\hline (2) & 112.5 & 110.7 & 1.8 & 1.6 \\
\hline (3) & 114.9 & 111.2 & 3.7 & 3.2 \\
\hline (4) & 109.4 & 119.2 & 9.8 & 9.0 \\
\hline (5) & 92.0 & 93.3 & 1.3 & 1.4 \\
\hline (6) & 105.0 & 102.0 & 3 & 2.9 \\
\hline (7) & 102.0 & 103.5 & 1.5 & 1.5 \\
\hline (8) & 178.0 & 182.3 & 4.3 & 2.4 \\
\hline (9) & 183.0 & 184.7 & 1.7 & 0.9 \\
\hline (10) & 173.0 & 165.2 & 7.8 & 4.5 \\
\hline (11) & 150.0 & 150.8 & 0.8 & 0.5 \\
\hline (12) & 166.1 & 167.2 & 1.1 & 0.7 \\
\hline (13) & 124.7 & 125.3 & 0.6 & 0.5 \\
\hline (14) & 103.0 & 109.7 & 6.7 & 6.5 \\
\hline (15) & 116.2 & 114.7 & 1.5 & 1.3 \\
\hline (16) & 109.6 & 109.5 & 0.1 & 0.1 \\
\hline (17) & 107.3 & 110.9 & 3.6 & 3.4 \\
\hline (18) & 91.3 & 96.5 & 5.2 & 5.7 \\
\hline (19) & 117.3 & 119.7 & 2.4 & 2.0 \\
\hline (20) & 121.9 & 113.2 & 8.7 & 7.1 \\
\hline (21) & 109.0 & 108.0 & 1 & 0.9 \\
\hline (22) & 100.9 & 97.8 & 3.1 & 3.1 \\
\hline (23) & 93.0 & 92.7 & 0.3 & 0.3 \\
\hline (24) & 98.6 & 91.8 & 6.8 & 6.9 \\
\hline (25) & 117.6 & 109.3 & 8.3 & 7.1 \\
\hline (26) & 105.9 & 108.1 & 2.2 & 2.1 \\
\hline (27) & 102.2 & 102.5 & 0.3 & 0.3 \\
\hline (28) & 87.8 & 86.8 & 1 & 1.1 \\
\hline (29) & 101.1 & 107.9 & 6.8 & 6.7 \\
\hline (30) & 118.5 & 126.2 & 7.7 & 6.5 \\
\hline (31) & 128.1 & 119.1 & 9 & 7.0 \\
\hline (32) & 105.3 & 105.1 & 0.2 & 0.2 \\
\hline (33) & 85.3 & 92.1 & 6.8 & 8.0 \\
\hline (34) & 119.8 & 109.4 & 10.4 & 8.7 \\
\hline (35) & 129.6 & 128.7 & 0.9 & 0.7 \\
\hline (36) & 117.4 & 119.6 & 2.2 & 1.9 \\
\hline (37) & 95.9 & 97.5 & 1.6 & 1.7 \\
\hline (38) & 88.1 & 95.2 & 7.1 & 8.1 \\
\hline (39) & 95.0 & 96.8 & 1.8 & 1.9 \\
\hline (40) & 96.2 & 96.4 & 0.2 & 0.2 \\
\hline (41) & 89.1 & 97.3 & 8.2 & 9.2 \\
\hline (42) & 130.0 & 131.1 & 1.1 & 0.8 \\
\hline (43) & 135.0 & 124.3 & 10.7 & 7.9 \\
\hline (44) & 138.0 & 139.9 & 1.9 & 1.4 \\
\hline (45) & 185.0 & 179.8 & 5.2 & 2.8 \\
\hline (46) & 166.0 & 161.8 & 4.2 & 2.5 \\
\hline (47) & 162.0 & 157.9 & 4.1 & 2.5 \\
\hline (48) & 181.0 & 181.9 & 0.9 & 0.5 \\
\hline (49) & 155.0 & 154.5 & 0.5 & 0.3 \\
\hline
\end{tabular}

TABle 5: Continued.

\begin{tabular}{|c|c|c|c|c|}
\hline Number & $A(\mathrm{MPa})$ & $P(\mathrm{MPa})$ & Abs (MPa) & $k(\%)$ \\
\hline$(50)$ & 159.0 & 149.2 & 9.8 & 6.2 \\
\hline (51) & 115.0 & 108.0 & 7 & 6.1 \\
\hline (52) & 122.0 & 117.2 & 4.8 & 3.9 \\
\hline (53) & 123.0 & 120.6 & 2.4 & 2.0 \\
\hline (54) & 109.0 & 108.7 & 0.3 & 0.3 \\
\hline (55) & 115.0 & 116.9 & 1.9 & 1.7 \\
\hline (56) & 117.0 & 113.8 & 3.2 & 2.7 \\
\hline (57) & 105.0 & 101.7 & 3.3 & 3.1 \\
\hline (58) & 109.0 & 108.2 & 0.8 & 0.7 \\
\hline (59) & 119.0 & 118.4 & 0.6 & 0.5 \\
\hline (60) & 86.0 & 89.2 & 3.2 & 3.7 \\
\hline (61) & 98.0 & 91.0 & 7 & 7.1 \\
\hline (62) & 92.0 & 98.2 & 6.2 & 6.7 \\
\hline (63) & 88.0 & 90.6 & 2.6 & 3.0 \\
\hline (64) & 93.0 & 88.2 & 4.8 & 5.2 \\
\hline (65) & 94.0 & 99.8 & 5.8 & 6.2 \\
\hline (66) & 150.0 & 149.6 & 0.4 & 0.3 \\
\hline (67) & 138.0 & 148.3 & 10.3 & 7.5 \\
\hline (68) & 135.0 & 139.9 & 4.9 & 3.6 \\
\hline (69) & 118.0 & 117.2 & 0.8 & 0.7 \\
\hline (70) & 162.0 & 153.7 & 8.3 & 5.1 \\
\hline (71) & 163.0 & 163.1 & 0.1 & 0.1 \\
\hline (72) & 165.0 & 168.2 & 3.2 & 1.9 \\
\hline (73) & 155.0 & 154.3 & 0.7 & 0.5 \\
\hline (74) & 158.0 & 158.6 & 0.6 & 0.4 \\
\hline (75) & 156.0 & 154.0 & 2 & 1.3 \\
\hline (76) & 143.0 & 147.4 & 4.4 & 3.1 \\
\hline (77) & 146.0 & 149.0 & 3 & 2.1 \\
\hline$(78)$ & 139.0 & 133.9 & 5.1 & 3.7 \\
\hline
\end{tabular}

$A=$ actual value, $P=$ predicted value, Abs $=|P-A|$, and $k=\mathrm{Abs} / A$.

(1) The addition of $30 \%$ FA decreases the compressive strength compared to that of the reference sample. However, with increased SF content, the compressive strength can be improved gradually. The UHPC made with 30\% FA and 20\% SF exhibited the highest flexural and compressive strengths of all mixtures tested. The UHPC made with $30 \% \mathrm{FA}$ and $10 \% \mathrm{SF}$ exhibited equivalent mechanical properties to those of the reference sample.

(2) Based on the experimental results, the efficiency factor ( $k$-value), which can be considered as synergic effect efficiency on compressive strength, is calculated. The highest $k$-value (1.03) was obtained with a ternary blend of cement containing 30\% FA and $20 \%$ SF, followed by the blend with $30 \% \mathrm{FA}$ and $10 \%$ SF (1.00). It can be concluded that it is possible to produce UHPCs with low cement content $\left(480 \mathrm{~kg} / \mathrm{m}^{3}\right)$.

(3) The microstructure observation and pore volume results indicate a strong correlation with the mechanical 


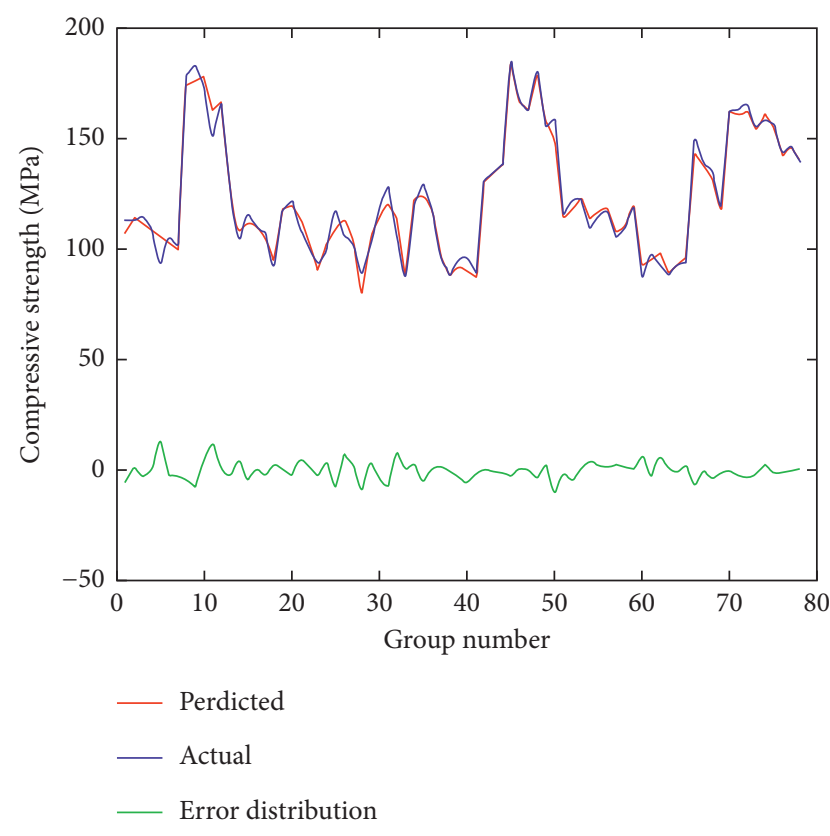

FIgURE 6: Evaluation of the actual value and predicted value.

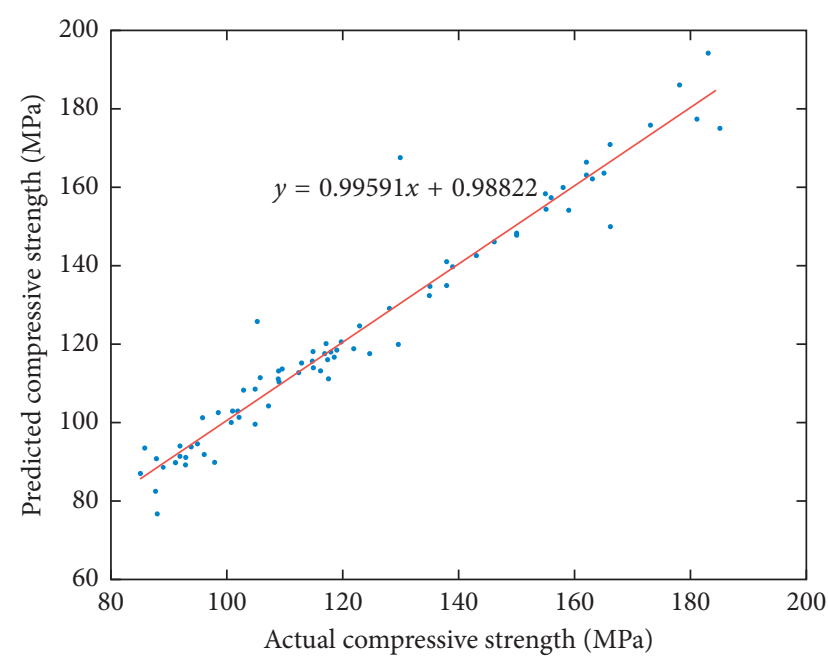

Figure 7: Performance of the prediction.

properties. The mixture with the densest matrix and the lowest number of capillary pores had the highest flexural and compressive properties. Furthermore, the $\mathrm{BJH}$ method is validated as an effective way to quantify the pore size distribution of UHPCs.

(4) The ANN model provides a highly accurate method of predicting the compressive strength of UHPCs containing FA and SF. The MAPE, RMSE, and $R^{2}$ demonstrate that it is feasible to predict the compressive strength of UHPCs containing SCMs with low error. If the input variables are obtained, the compressive strength of UHPCs can be determined. The inclusion of input variables such as the water-tocement equivalent ratio, the aggregate-to-cement equivalent ratio, and the difference between the minimum and maximum values of the aggregate

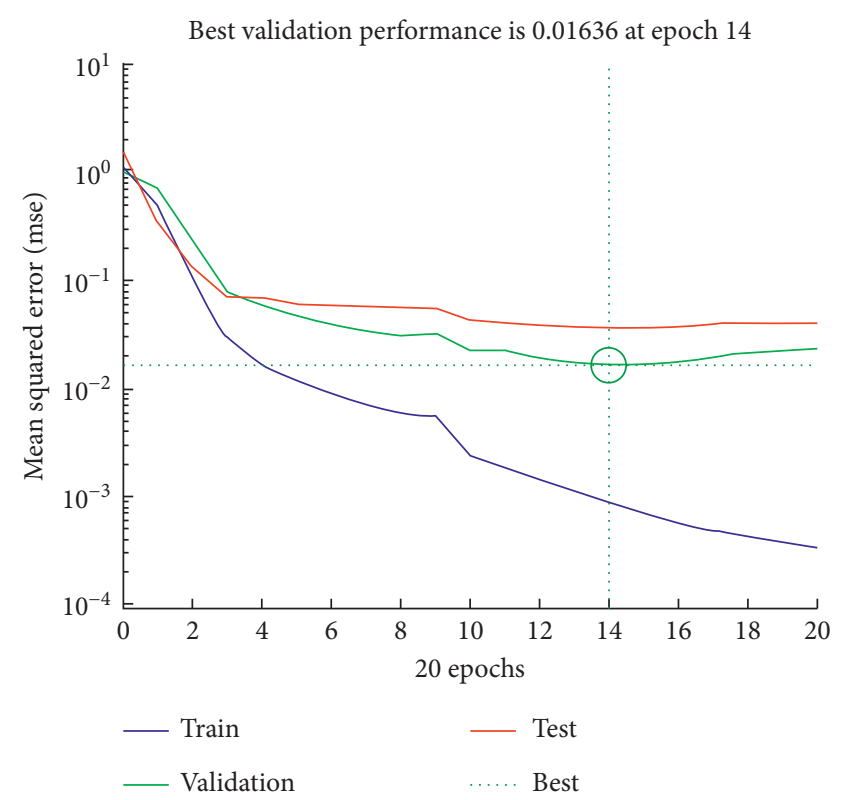

Figure 8: Evaluation of the model for compressive strength.

contributed greatly to the accuracy of the prediction results.

(5) It can be expected that the other properties of UHPCs, such as the modulus of elasticity, chloride penetration, shrinkage, and carbonisation, could be predicted using an ANN model. Although this study focused on UHPCs, the developed model could be applied to similar concretes or extended by considering three or more supplementary materials.

\section{Disclosure}

This paper was presented in part at the IOP Conference Series: Earth and Environmental Science 61 (2017).

\section{Conflicts of Interest}

The authors declare that there are no conflicts of interest regarding the publication of this paper.

\section{Acknowledgments}

The authors gratefully acknowledge the use of the services and facilities of Cardiff BIM \& Virtual Reality Laboratory and BRE Trust Centre for Sustainable Engineering at the Cardiff University. The authors also would like to acknowledge the support provided by the China Scholarship Council (CSC no. 201606570007) for partially funding this research.

\section{References}

[1] R. Yu, P. Spiesz, and H. J. H. Brouwers, "Mix design and properties assessment of ultra-high performance fibre reinforced concrete (UHPFRC)," Cement and Concrete Research, vol. 56, pp. 29-39, 2014. 
[2] R. Yu, P. Spiesz, and H. J. H. Brouwers, "Development of ultra-high performance fibre reinforced concrete (UHPFRC): towards an efficient utilization of binders and fibres," Construction and Building Materials, vol. 79, pp. 273-282, 2015.

[3] M. C. G. Juenger and R. Siddique, "Recent advances in understanding the role of supplementary cementitious materials in concrete," Cement and Concrete Research, vol. 78, pp. 7180, 2015.

[4] E. Ghafari, H. Costa, E. Júlio, A. Portugal, and L. Durães, "The effect of nanosilica addition on flowability, strength and transport properties of ultra high performance concrete," Materials \& Design, vol. 59, pp. 1-9, 2014.

[5] M. A. A. Aldahdooh, N. M. Bunnori, and M. M. Johari, "Evaluation of ultra-high-performance-fiber reinforced concrete binder content using the response surface method," Materials \& Design, vol. 52, pp. 957-965, 2013.

[6] S. Zhang, E. Worrell, and W. C. Graus, "Evaluating cobenefits of energy efficiency and air pollution abatement in China's cement industry," Applied Energy, vol. 147, pp. 192213, 2015.

[7] S. M. Mousavi, P. Aminian, A. H. Gandomi, A. H. Alavi, and H. Bolandi, "A new predictive model for compressive strength of HPC using gene expression programming," Advances in Engineering Software, vol. 45, no. 1, pp. 105-114, 2012.

[8] H. I. Erdal, "Two-level and hybrid ensembles of decision trees for high performance concrete compressive strength prediction," Engineering Applications of Artificial Intelligence, vol. 26, no. 7, pp. 1689-1697, 2013.

[9] I. C. Yeh, "Modeling of strength of high-performance concrete using artificial neural networks," Cement and Concrete Research, vol. 28, no. 12, pp. 1797-1808, 1998.

[10] H. J. H. Brouwers and H. J. Radix, "Self-compacting concrete: theoretical and experimental study," Cement and Concrete Research, vol. 35, no. 11, pp. 2116-2136, 2005.

[11] BS EN 196-1:2016, Methods of Testing Cement. Determination of Strength, BSI Standards Publication, London, UK, 2016.

[12] E. P. Barrett, L. G. Joyner, and P. P. Halenda, "The determination of pore volume and area distributions in porous substances.I. Computations from nitrogen isotherms," Journal of the American Chemical Society, vol. 73, no. 1, pp. 373-380, 1951.

[13] C. Shi, D. Wang, L. Wu, and Z. Wu, "The hydration and microstructure of ultra high-strength concrete with cement-silica fume-slag binder," Cement and Concrete Composites, vol. 61, pp. 44-52, 2015.

[14] H. Yazıcı, H. Yiğiter, A. S. Karabulut, and B. Baradan, "Utilization of fly ash and ground granulated blast furnace slag as an alternative silica source in reactive powder concrete," Fuel, vol. 87, no. 12, pp. 2401-2407, 2008.

[15] H. T. Le, M. Müller, K. Siewert, and H. M. Ludwig, "The mix design for self-compacting high performance concrete containing various mineral admixtures," Materials \& Design, vol. 72, pp. 51-62, 2015.

[16] BS EN 206:2013, Concrete-Specification, Performance, Production and Conformity, BSI Standards Publication, London, UK, 2013.

[17] H. S. Wong and H. A. Razak, "Efficiency of calcined kaolin and silica fume as cement replacement material for strength performance," Cement and Concrete Research, vol. 35, no. 4, pp. 696-702, 2005.

[18] H. M. Jennings and P. D. Tennis, "Model for the developing microstructure in Portland cement pastes," Journal of the American Ceramic Society, vol. 77, no. 12, pp. 3161-3172, 1994.
[19] K. S. W. Sing, "Characterization of porous materials: past, present and future," Colloids and Surfaces A: Physicochemical and Engineering Aspects, vol. 241, no. 1-3, pp. 3-7, 2004.

[20] G. Quercia, A. Lazaro, J. W. Geus, and H. J. H. Brouwers, "Characterization of morphology and texture of several amorphous nano-silica particles used in concrete," Cement and Concrete Composites, vol. 44, pp. 77-92, 2013.

[21] H. Yiğiter, S. Aydın, H. Yazıcı, and M. Y. Yardımcı, "Mechanical performance of low cement reactive powder concrete (LCRPC)," Composites Part B: Engineering, vol. 43, no. 8, pp. 2907-2914, 2012.

[22] N. Randl, T. Steiner, S. Ofner, E. Baumgartner, and T. Mészöly, "Development of UHPC mixtures from an ecological point of view," Construction and Building Materials, vol. 67, pp. 373378, 2014.

[23] R. Yu, P. Spiesz, and H. J. H. Brouwers, "Development of an eco-friendly ultra-high performance concrete (UHPC) with efficient cement and mineral admixtures uses," Cement and Concrete Composites, vol. 55, pp. 383-394, 2015.

[24] Y. Li and A. K. H. Kwan, "Ternary blending of cement with fly ash microsphere and condensed silica fume to improve the performance of mortar," Cement and Concrete Composites, vol. 49, pp. 26-35, 2014.

[25] C. Wang, C. Yang, F. Liu, C. Wan, and X. Pu, "Preparation of ultra-high performance concrete with common technology and materials," Cement and Concrete Composites, vol. 34, no. 4, pp. 538-544, 2012.

[26] K. Wille and C. B. Cotulio, "Material efficiency in the design of ultra-high performance concrete," Construction and Building Materials, vol. 86, pp. 33-43, 2015.

[27] C. H. Lim, Y. S. Yoon, and J. H. Kim, "Genetic algorithm in mix proportioning of high-performance concrete," Cement and Concrete Research, vol. 34, no. 3, pp. 409-420, 2004.

[28] V. Corinaldesi and G. Moriconi, "Mechanical and thermal evaluation of Ultra High Performance Fiber Reinforced Concretes for engineering applications," Construction and Building Materials, vol. 26, no. 1, pp. 289-294, 2012.

[29] J. Zhang and Y. Zhao, "Development of sustainable ultra-high performance concrete," IOP Conference Series: Earth and Environmental Science, vol. 61, p. 012076, 2017. 

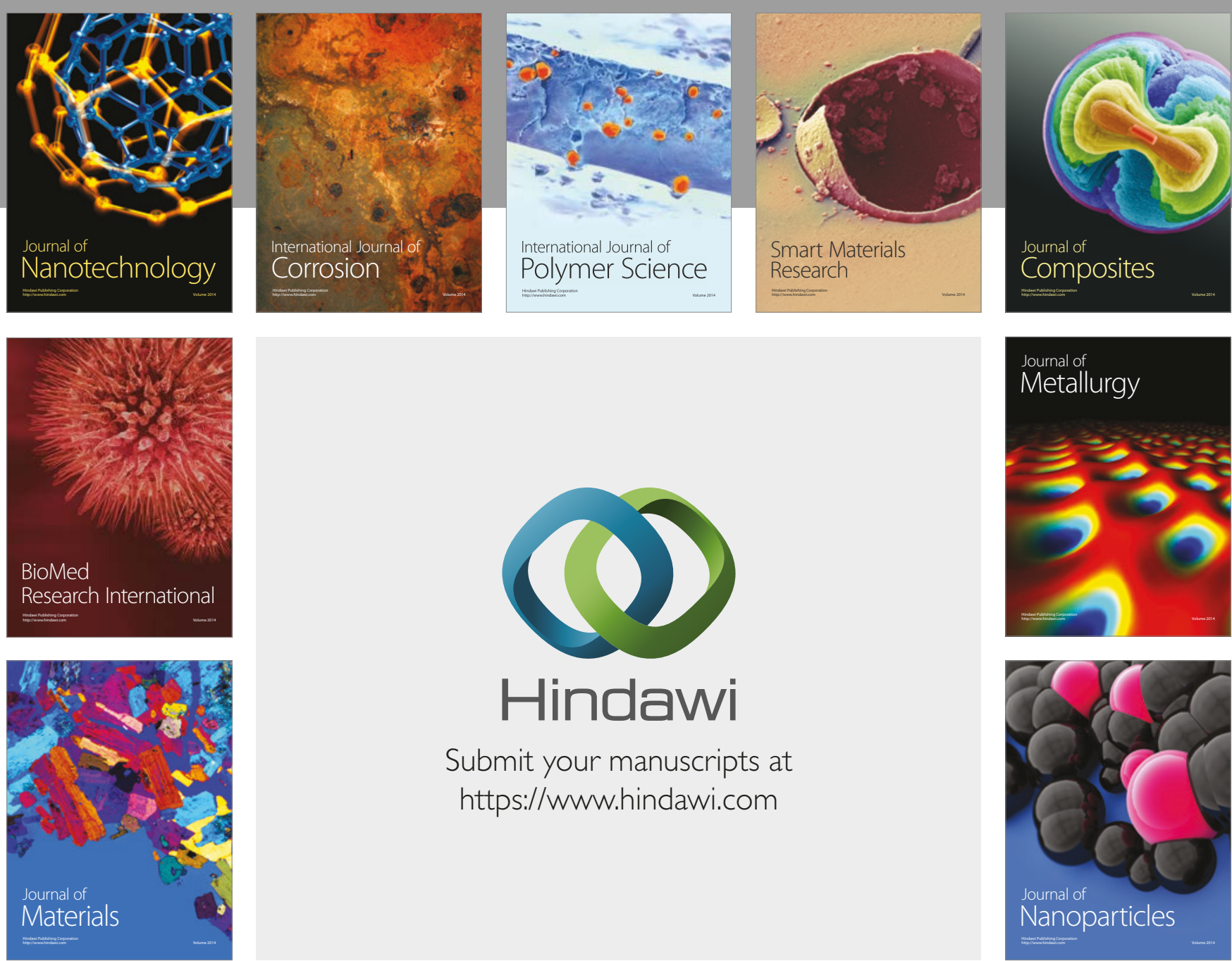

\section{Hindawi}

Submit your manuscripts at

https://www.hindawi.com
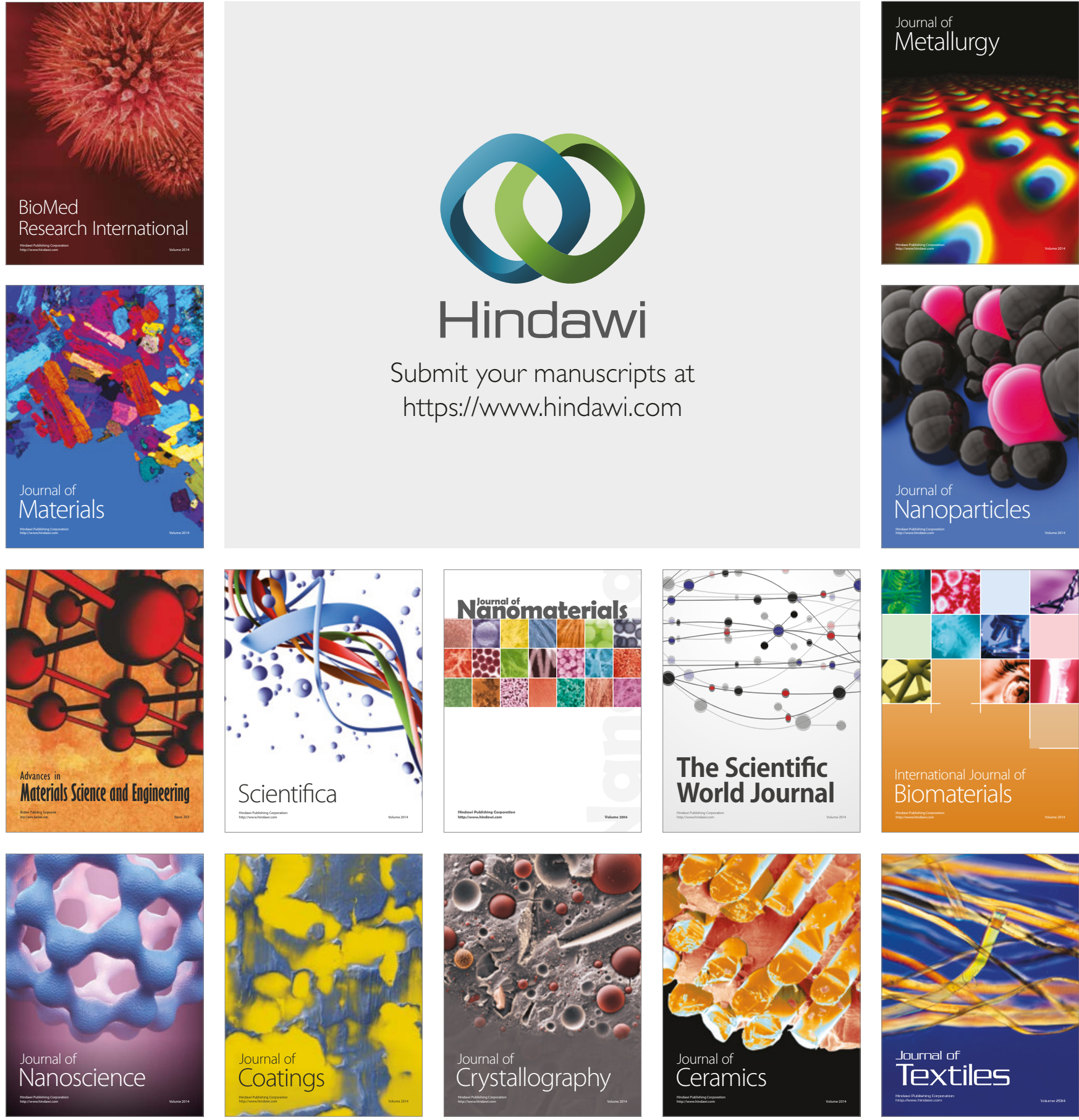

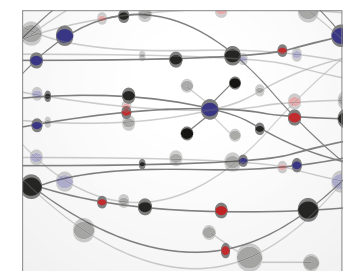

The Scientific World Journal
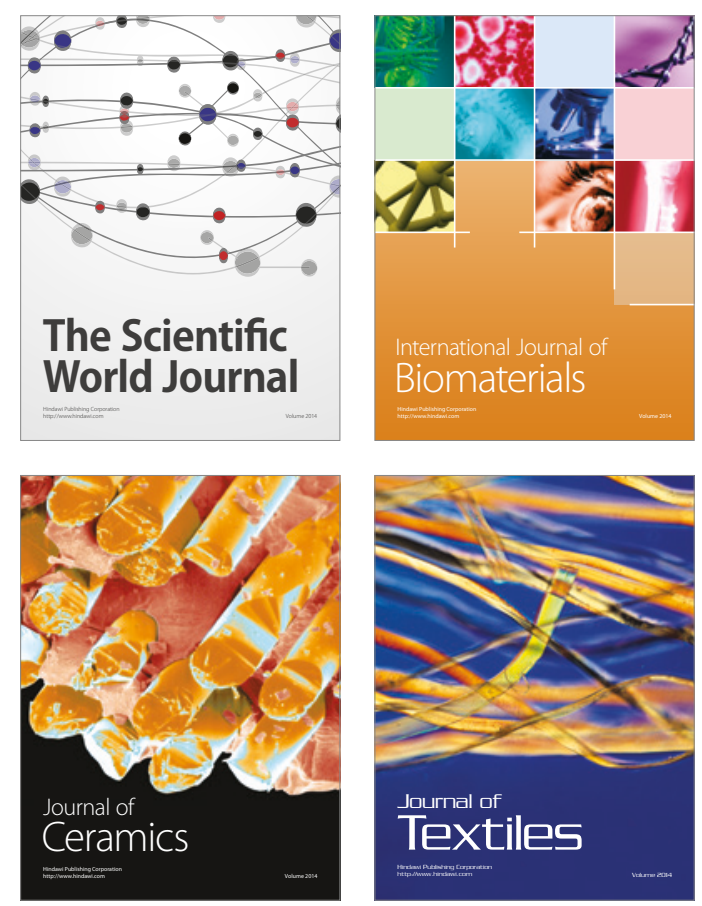